\title{
Potential role for interferon gamma in the treatment of recurrent ventilator-acquired pneumonia in patients with COVID-19: a hypothesis
}

\author{
Lee S. Nguyen ${ }^{1,2}, Z_{\text {Zakaria Ait Hamou }}^{1,5}$, Nabil Gastli $^{3}$, Nicolas Chapuis ${ }^{4,5}$ and Frédéric Pène ${ }^{1,5^{*}}$ (])
}

() 2021 Springer-Verlag GmbH Germany, part of Springer Nature

\section{Dear Editor,}

The pathophysiology of pneumonia caused by SARS$\mathrm{CoV}-2$ infection is related to defective antiviral immunity and protracted systemic and pulmonary inflammation. Severe coronavirus disease 2019 (COVID-19)-related pneumonia often requires prolonged mechanical ventilation, related to the primary pulmonary insult and to a particular susceptibility to secondary ventilator-associated pneumonia (VAP) [1, 2]. Monocyte deactivation, as assessed by decreased monocytic HLA-DR (mHLA-DR) expression, has been associated with increased risks of intensive care unit (ICU)-acquired infections in various conditions including bacterial sepsis, acute respiratory distress syndrome or trauma [3]. In patients with COVID-19-related pneumonia, decreased mHLA-DR expression is associated with the development of severe respiratory failure, and presumably may contribute to pronounced susceptibility to bacterial superinfections $[4$, 5].

In line with this hypothesis, we report six non-immunocompromised patients who sustained recurrent VAP despite adapted courses of antibiotics, thereby suggestive of defective anti-infective responses. Patients were assessed for mHLA-DR expression and were then administered interferon (IFN)-gamma to restore activated monocytes and thereby improve lung defense.

*Correspondence: frederic.pene@aphp.fr

1 Service de Médecine Intensive-Réanimation, Hôpital Cochin, AP-HP. Centre, 27 rue du Faubourg Saint-Jacques, 75014 Paris, France

Full author information is available at the end of the article
VAP was diagnosed in patients under invasive mechanical ventilation for at least $48 \mathrm{~h}$ fulfilling the following criteria: (i) clinical manifestations (purulent sputum, fever, deterioration of oxygenation and/or new-onset or worsening shock); (ii) radiographic infiltrates; (iii) positive cultures of endotracheal aspirates for pathogenic bacteria $\left(\geq 10^{5}\right.$ colony-forming units/mL). mHLA-DR expression was assessed by flow cytometry and was reported as the proportion of HLA-DR ${ }^{\text {high }}$ monocytes (supplementary figure 1). The significant decrease in mHLA-DR expression prompted a 5-day course of IFN-gamma (100 $\mu \mathrm{g} /$ day subcutaneous). mHLA-DR expression was monitored at days 3, 5, and 8 following IFN-gamma initiation.

All patients had experienced at least two prior episodes of VAP, caused by at least one of the same putative bacteria (supplementary table 1). The new VAP episode resulted in oxygenation impairment and acute circulatory failure requiring vasopressors in all patients. Antibiotic treatment was optimized based on antimicrobial susceptibility testing and antibiotic plasmatic concentration, and was prolonged (median 14 days, interquartile range [14-21]). Time courses of mHLA-DR expression and total lymphocyte counts are displayed in the Fig. 1. IFNgamma treatment led to a fast increase in HLA-DR ${ }^{\text {high }}$ monocytes in all but one patient with rapidly fatal septic shock (patient \#3). Two additional patients died from bleeding complication (patient \#5) and from late septic shock (patient \#6) unrelated to VAP. The three remaining patients improved their respiratory condition without further recurrence of VAP (supplementary figure 3), and finally recovered to be discharged from the ICU. 

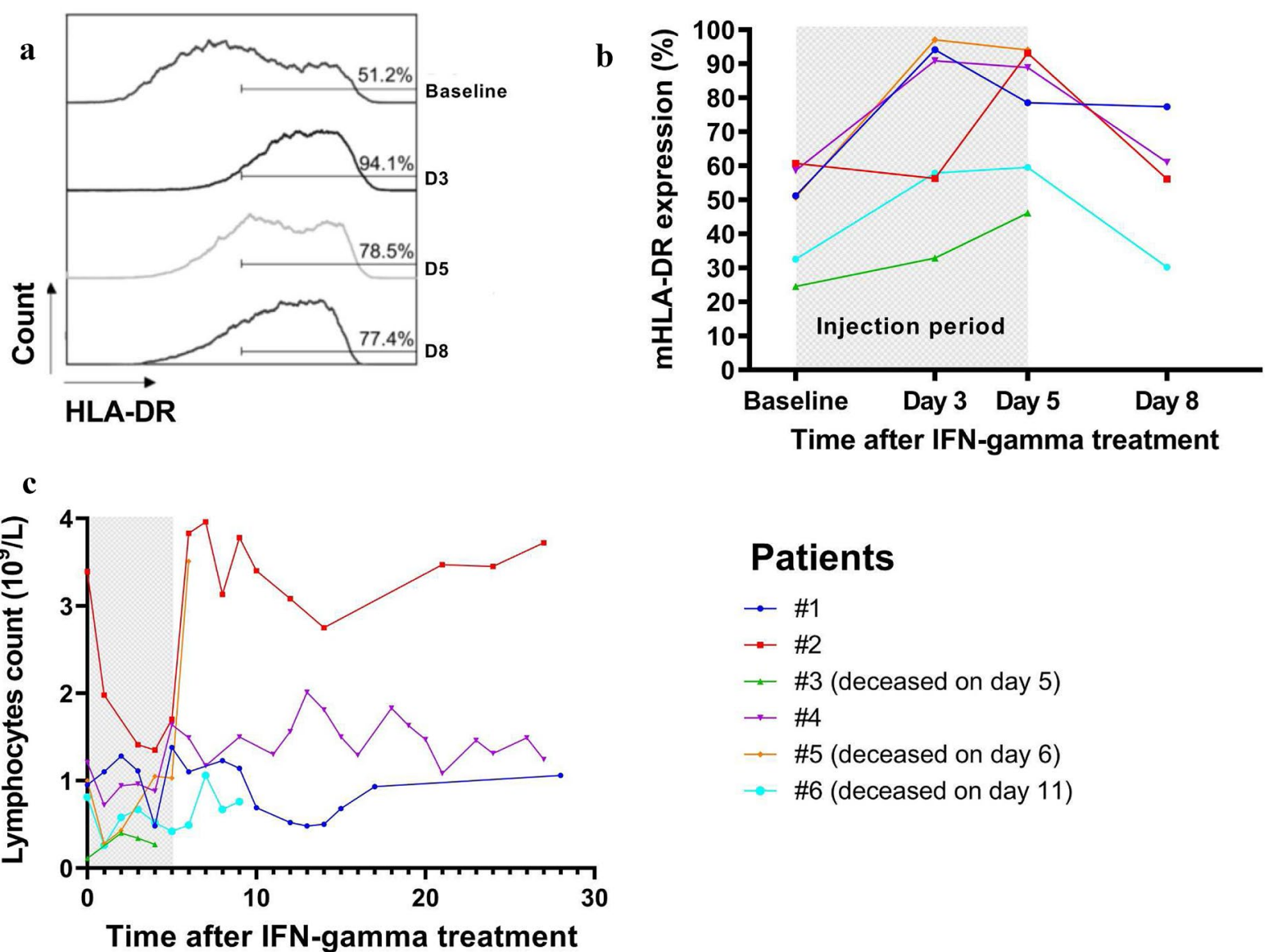

Fig. 1 Impact of interferon gamma treatment on immune parameters. a Representative example of the evolution of HLA-DR ${ }^{\text {high }}$ monocytes after 5-day interferon gamma (IFN-gamma) treatment in patient \#1. b Evolution of monocytic HLA-DR (mHLA-DR) expression (proportion of HLA-DR high monocytes) over time following IFN-gamma administration. c Time course of total lymphocyte counts following IFN-gamma administration

IFN-gamma was well tolerated without any attributable side effects.

These results point toward a plausible efficacy of IFNgamma in the treatment of recurrent VAP through restoration of monocyte activation. These results are exploratory but echo previous reports of IFN-gamma treatment efficacy in superinfections complicating bacterial sepsis [6]. IFN-gamma treatment was based on mHLA-DR expression, a reliable biomarker of postaggressive immune suppression, thereby accounting for a good example of personalized medicine in critically ill patients.

Besides early anti-inflammatory approaches to treat severe COVID-19 pneumonia, our results raise the question of immunostimulant therapies to fight recurrent bacterial superinfections in critically ill patients later in the course of the disease.

\section{Supplementary Information}

The online version contains supplementary material available at https://doi. org/10.1007/s00134-021-06377-3.

\section{Author details}

${ }^{1}$ Service de Médecine Intensive-Réanimation, Hôpital Cochin, AP-HP. Centre, 27 rue du Faubourg Saint-Jacques, 75014 Paris, France. ${ }^{2}$ Research and Innovation Department, CMC Ambroise Paré, RICAP, Neuilly-sur-Seine, France. ${ }^{3}$ Service de Bactériologie, Hôpital Cochin, AP-HP. Centre, Université de Paris, Paris, France. ${ }^{4}$ Service d'Hématologie, Hôpital Cochin, AP-HP. Centre, Université de Paris, Paris, France. ${ }^{5}$ Institut Cochin, INSERM U1016, CNRS UMR8104, Université de Paris, Paris, France.

\section{Acknowledgements}

We thank all attending physicians who helped manage these patients, in particular, Valentin Landon, Philippe Estagnasie and Pierre Squara.

\section{Declarations}

\section{Conflict of interest}

LSN has no conflict of interest regarding this work. ZAH has no conflict of interest regarding this work. NG has no conflict of interest regarding this work. NC has no conflict of interest regarding this work. FP received an institutional grant from ALEXION, and personal fees from GILEAD, outside of this work. 


\section{Consent to publish}

This work was approved by an institutional review board committee (CMCAP \#00012608-2021-01). All patients or their next-of-kin gave consent to publish the individual cases.

\section{Publisher's Note}

Springer Nature remains neutral with regard to jurisdictional claims in published maps and institutional affiliations.

Received: 12 January 2021 Accepted: 1 March 2021

Published online: 10 March 2021

\section{References}

1. Llitjos JF, Bredin S, Lascarrou JB, Soumagne T, Cojocaru M, Leclerc M, Lepetit A, Gouhier A, Charpentier J, Piton G, Faron M, Stoclin A, Pène F (2021) Increased susceptibility to intensive care unit-acquired pneumonia in severe COVID-19 patients: a multicentre retrospective cohort study. Ann Intensive Care 11:20

2. Rouzé A, Martin-Loeches I, Povoa P, Makris D, Artigas A, Bouchereau M, Lambiotte F, Metzelard M, Cuchet P, Boulle Geronimi C, Labruyere M, Tamion F, Nyunga M, Luyt CE, Labreuche J, Pouly O, Bardin J, Saade A, Asfar P, Baudel JL, Beurton A, Garot D, loannidou I, Kreitmann L, Llitjos JF, Magira E, Megarbane B, Meguerditchian D, Moglia E, Mekontso-Dessap A, Reignier J, Turpin M, Pierre A, Plantefeve G, Vinsonneau C, Floch PE, Weiss
N, Ceccato A, Torres A, Duhamel A, Nseir S (2021) Relationship between SARS-CoV-2 infection and the incidence of ventilator-associated lower respiratory tract infections: a European multicenter cohort study. Intensive Care Med 47:188-198

3. Conway Morris A, Datta D, Shankar-Hari M, Stephen J, Weir CJ, Rennie J, Antonelli J, Bateman A, Warner N, Judge K, Keenan J, Wang A, Burpee T, Brown KA, Lewis SM, Mare T, Roy Al, Hulme G, Dimmick I, Rossi AG, Simpson AJ, Walsh TS (2018) Cell-surface signatures of immune dysfunction risk-stratify critically ill patients: INFECT study. Intensive Care Med 44:627-635

4. Giamarellos-Bourboulis EJ, Netea MG, Rovina N, Akinosoglou K, Antoniadou A, Antonakos N, Damoraki G, Gkavogianni T, Adami ME, Katsaounou P, Ntaganou M, Kyriakopoulou M, Dimopoulos G, Koutsodimitropoulos I, Velissaris D, Koufargyris P, Karageorgos A, Katrini K, Lekakis V, Lupse M, Kotsaki A, Renieris G, Theodoulou D, Panou V, Koukaki E, Koulouris N, Gogos C, Koutsoukou A (2020) Complex immune dysregulation in COVID-19 patients with severe respiratory failure. Cell Host Microbe 27(992-1000):e1003

5. Benlyamani I, Venet F, Coudereau R, Gossez M, Monneret G (2020) Monocyte HLA-DR measurement by flow cytometry in COVID-19 patients: an interim review. Cytometry A 97:1217-1221

6. Payen D, Faivre V, Miatello J, Leentjens J, Brumpt C, Tissieres P, Dupuis C, Pickkers P, Lukaszewicz AC (2019) Multicentric experience with interferon gamma therapy in sepsis induced immunosuppression. A case series. BMC Infect Dis 19:931 